\section{Costs and consequences of enhanced primary care}

\section{for depression}

\author{
Systematic review of randomised economic evaluations
}

SIMON GILBODY, PETER BOWER and PAULA WHITTY
A number of organisational and educational strategies have been proposed to improve the recognition and management of depression in primary care (Gilbody et al, 2003; Bower \& Gilbody, 2005). These include educative strategies targeted at primary care physicians; clinical practice guidelines and a range of strategies to implement them (Cabana et al, 2002); and collaborative care, involving an enhanced case management role for nonmedical specialists such as practice nurses and integrated working relationships between primary care and specialist/ secondary services (Katon et al, 2001b).

In the UK, educational interventions based upon consensus guidelines have formed the cornerstone of quality improvement strategies, such as the Defeat Depression Campaign (Paykel \& Priest, 1992). More recently more intensive organisational strategies such as case management and stepped care have been cautiously recommended by the National Institute for Clinical Excellence (2004). In addition, there are specific governmental initiatives to encourage primary care physicians to provide 'enhanced care' for depression (National Institute for Mental Health in England, 2004), with economic incentives attached.

Decision-makers increasingly seek information on both clinical effectiveness and cost-effectiveness, in order to make optimal decisions about the use of limited healthcare resources (NHS Centre for Reviews and Dissemination, 2001a). Systematic reviews of randomised controlled trials are considered the highest quality source of research evidence, but this method of data synthesis has not hitherto been applied to economic data in this area of practice and policy. We therefore conducted a systematic review of economic evaluations of methods of organising and delivering enhanced primary healthcare for depression.

\section{METHOD}

We conducted a systematic review of economic studies according to accepted guidelines (NHS Centre for Reviews and Dissemination, 2001b), and specifically used a method proposed by Nixon et al (2001) to summarise data from individual economic evaluations where meta-analysis cannot routinely be applied.

\section{Inclusion criteria}

Economic studies were selected that examined the cost-effectiveness of organisational interventions to improve the quality and outcome or care for depression in primary care settings. These organisational interventions could include:

(a) clinician education;

(b) dissemination and implementation of treatment or management guidelines;

(c) reconfiguration of roles within primary care;

(d) case management or active follow-up;

(e) consultation-liaison or other methods of improving working relationships between primary care and specialist/ secondary services.

Studies that specifically examined the effectiveness of psychotherapy or drug treatments alone (e.g. Lave et al, 1998) were not included, although many of the enhancements outlined above included these as components of care. We sought all full economic evaluations (cost-benefit analyses, cost-effectiveness analyses, costminimisation analyses or cost-utility analyses) based upon robust randomised epidemiological designs (Gold et al, 1996; Drummond et al, 1997) - see the Appendix for definitions and examples of these terms.

\section{Search strategies}

We searched the following databases from inception to November 2005: Medline, EMBASE, CINAHL, PsycLIT, EconLIT, the Cochrane Library, the NHS Economic Evaluations Database, the Health Economic Evaluations Database and the Database of Abstracts of Reviews of Effectiveness. Search strategies included search terms relating to depression; primary care and quality improvement strategies, developed from strategies used within the Cochrane Effective Practice and Organisation of Care group (Bero et al, 1998) and optimal search strategies developed by the 
National Health Service Centre for Reviews and Dissemination (NHS Centre for Reviews and Dissemination, 2001a,b). In addition, we scrutinised the reference lists of all potentially relevant studies and corresponded with authors of randomised controlled trials for unpublished costeffectiveness data.

\section{Data extraction and synthesis}

The eligibility, design, content, quality and results of all full economic evaluations were judged against standard criteria (Drummond \& Jefferson, 1996; NHS Centre for Reviews and Dissemination, 2001a). Main betweengroup comparisons were considered in preference to non-randomised subgroup analyses. All prices were converted to UK pounds and US dollars using a common current exchange rate. A narrative overview of interventions, key design features, results and common methodological strengths and weaknesses was conducted. We paid particular attention to the use of appropriate

\section{INCREMENTAL EFFECTIVENESS}

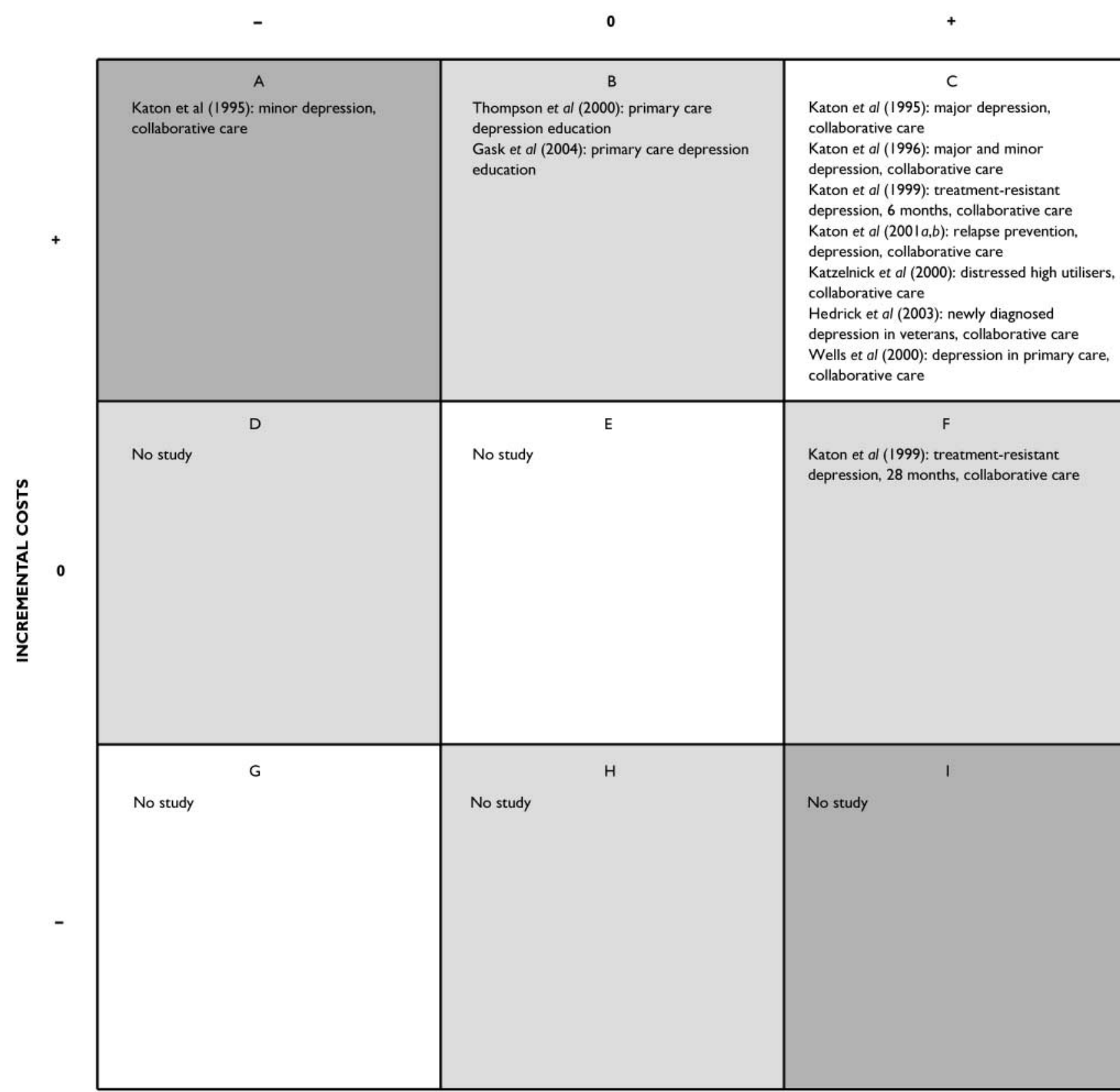

Decision strongly favoured (A, reject treatment; I, accept treatment)

Decision less favoured (B, D, reject treatment; $F, H$, accept treatment)

No obvious decision (C, is added effect worth the extra cost? G, is reduced effect acceptable at reduced cost? $E$, neutral cost and effect: other reasons to adopt treatment?)

Fig. I Permutation matrix for possible outcomes of economic evaluations for study of intervention v. comparator following the method proposed by Nixon et al (200I). Effectiveness: +, better; 0 , same; -, poorer. Cost: + , higher; 0 , same; - , lower. 


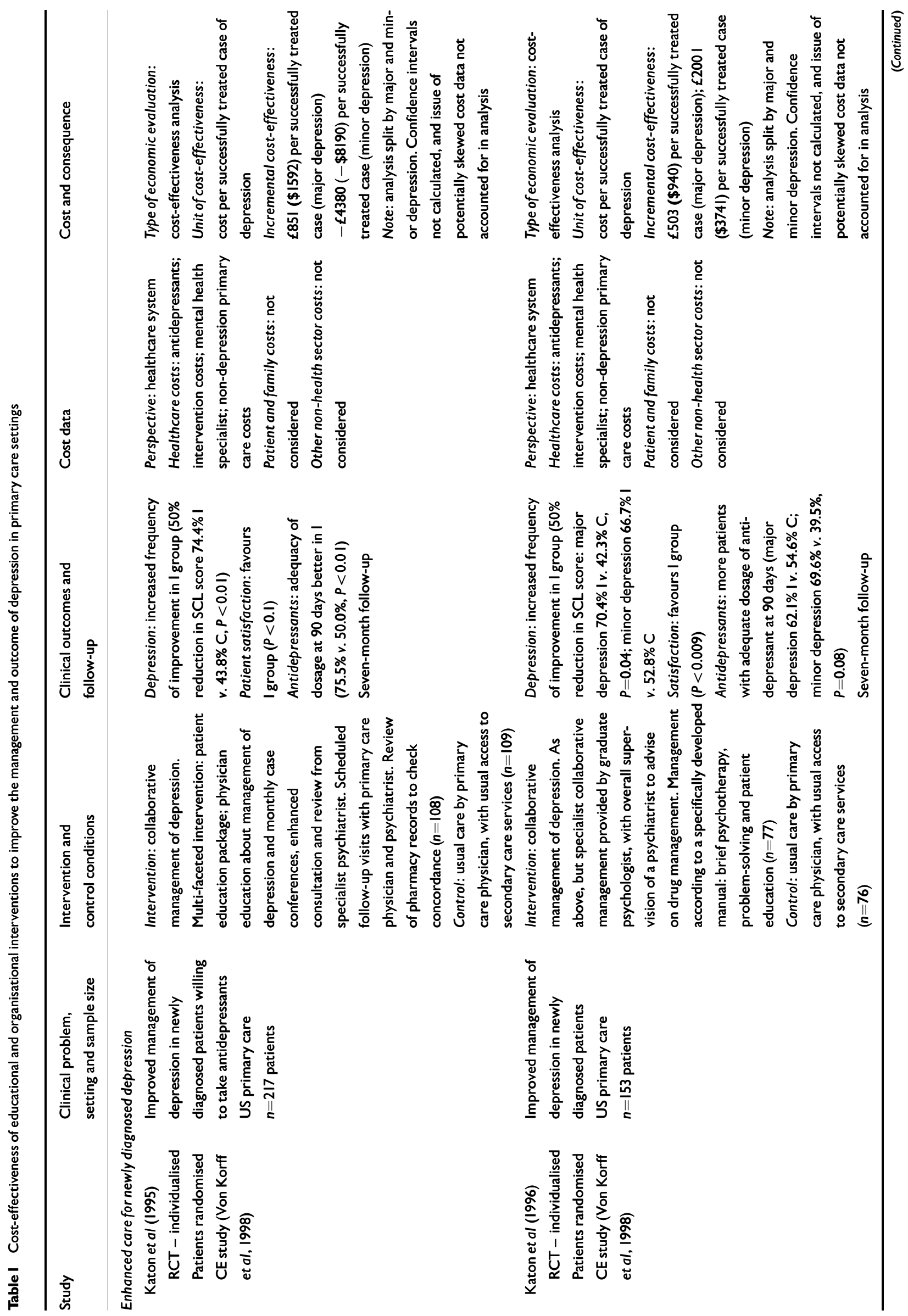




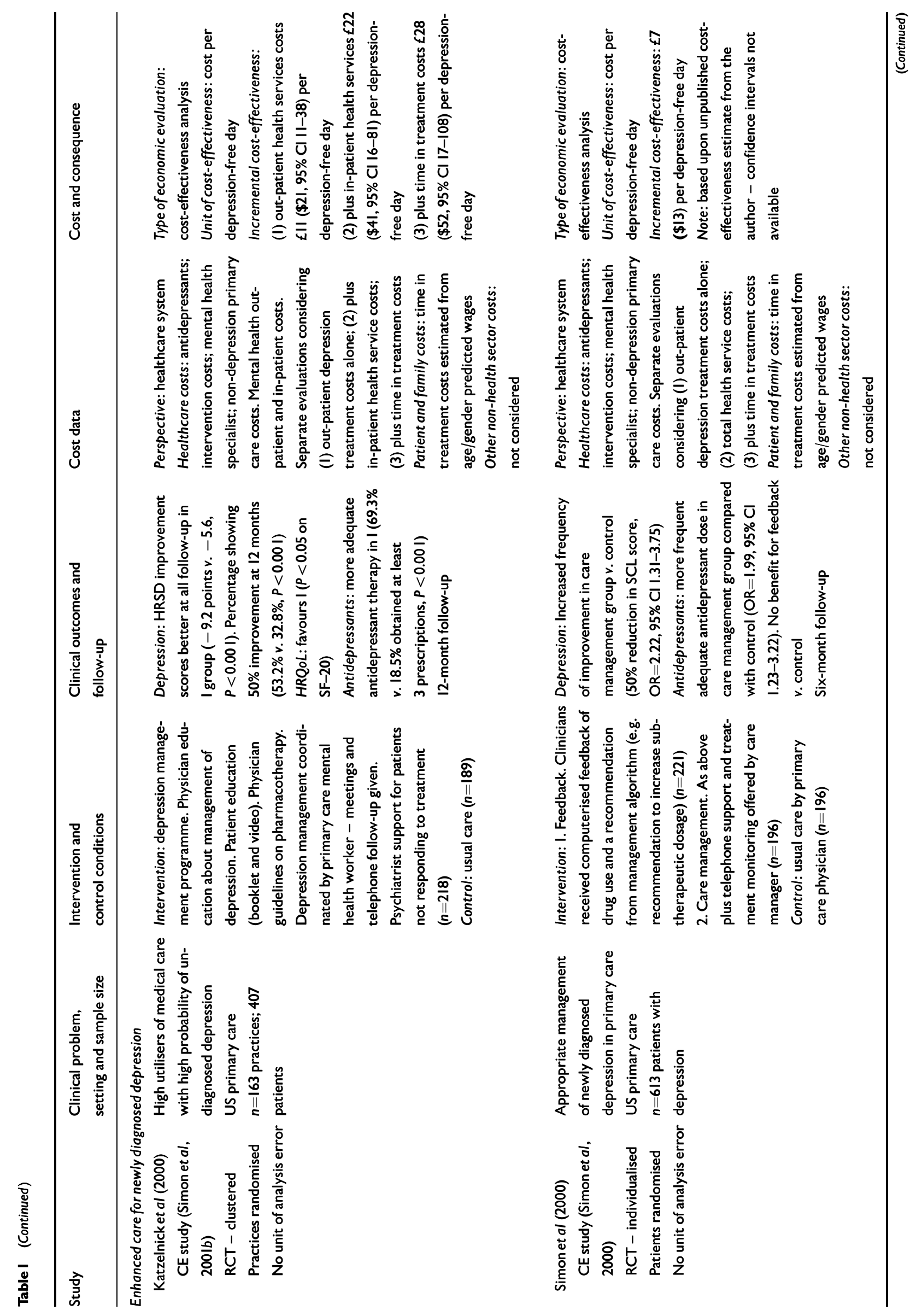




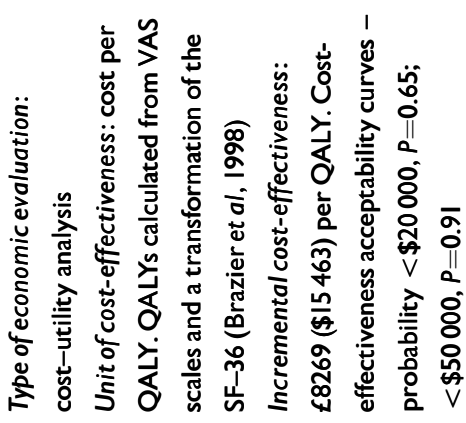

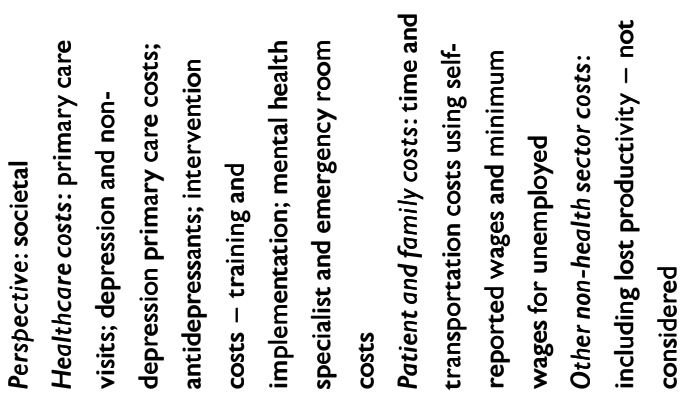

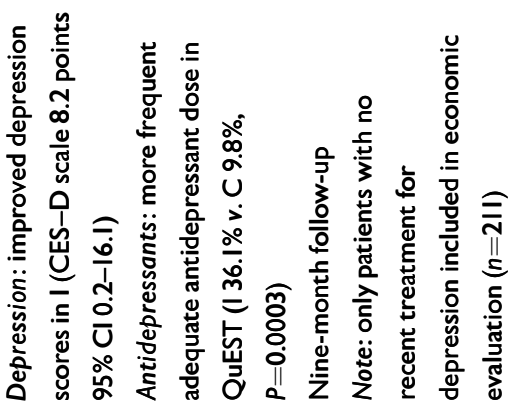
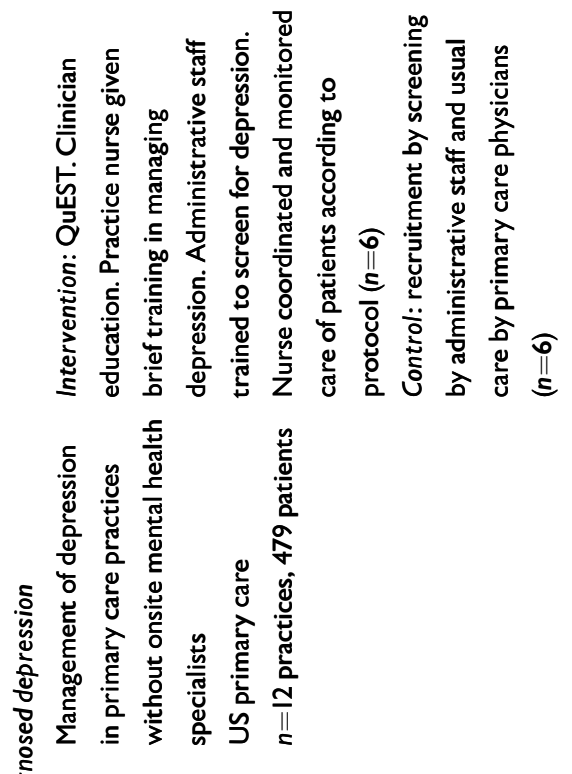

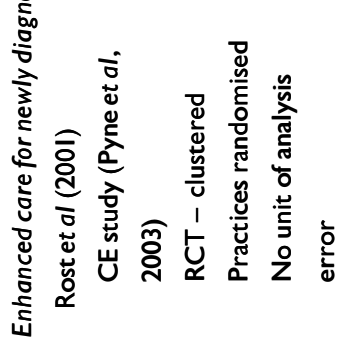
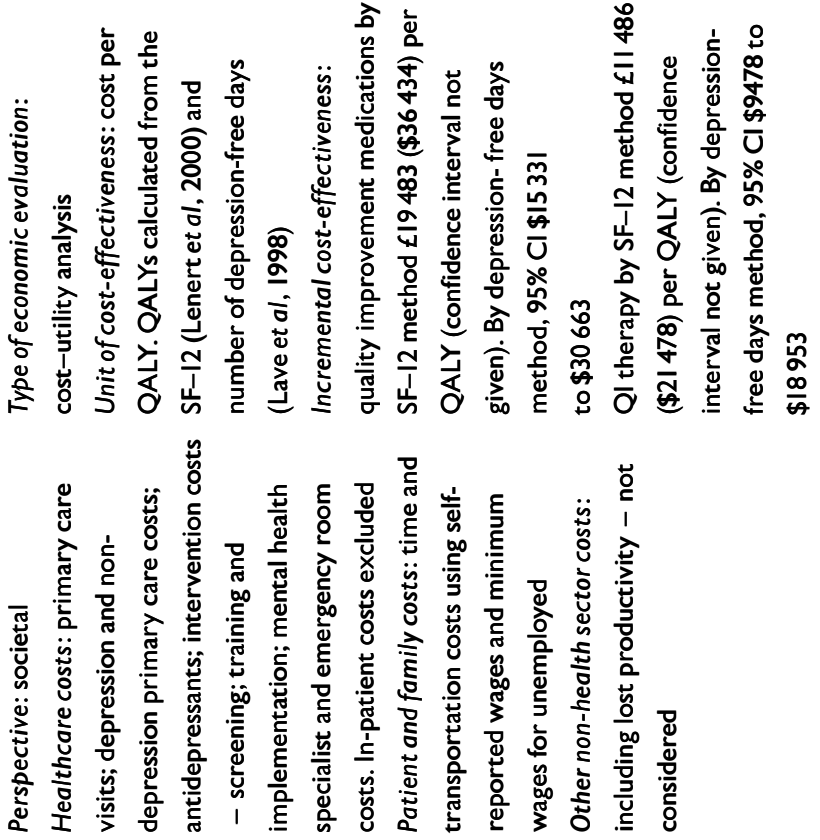

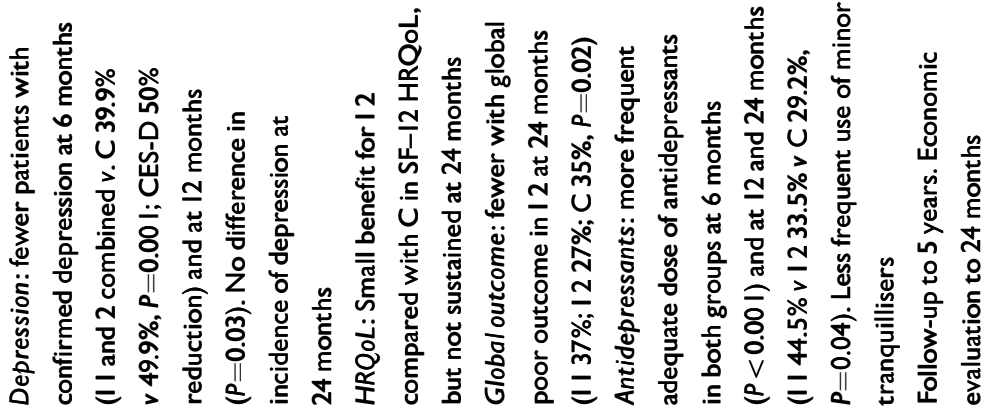
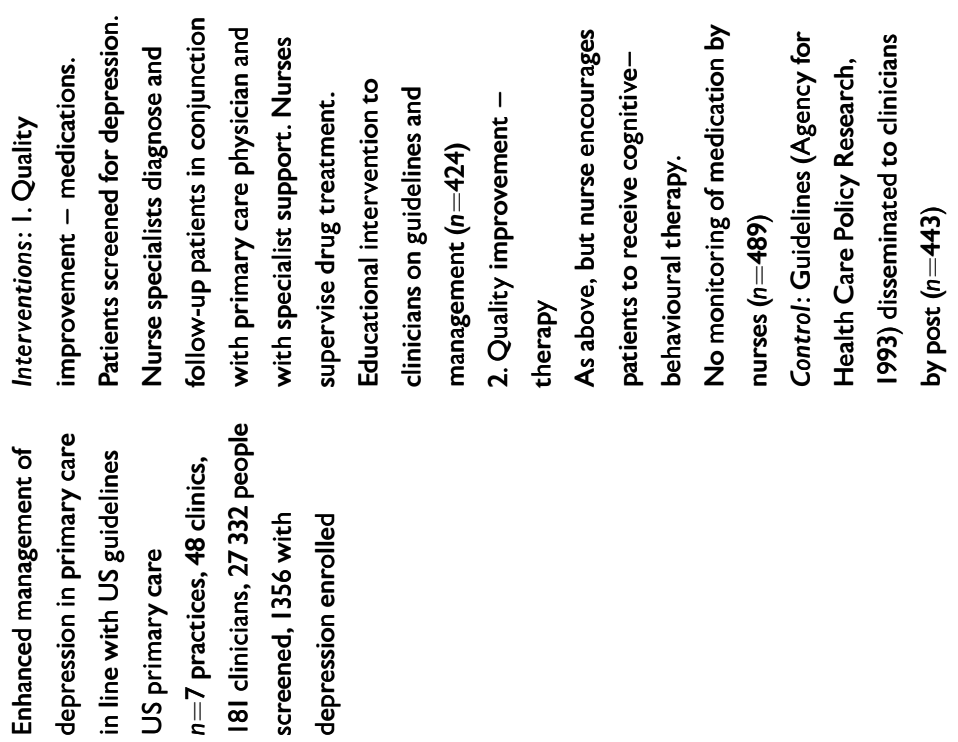

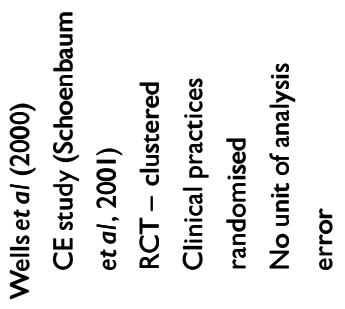




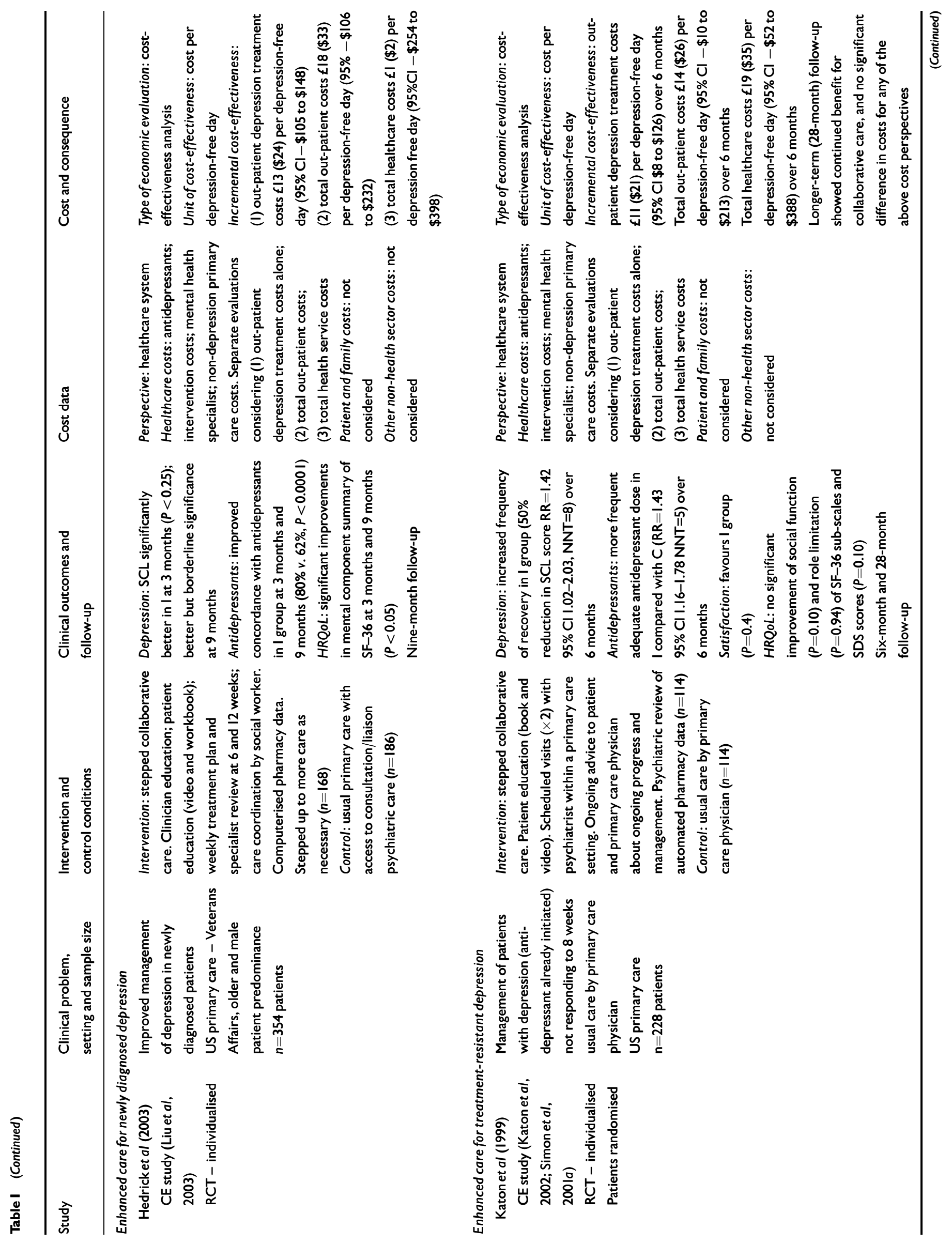




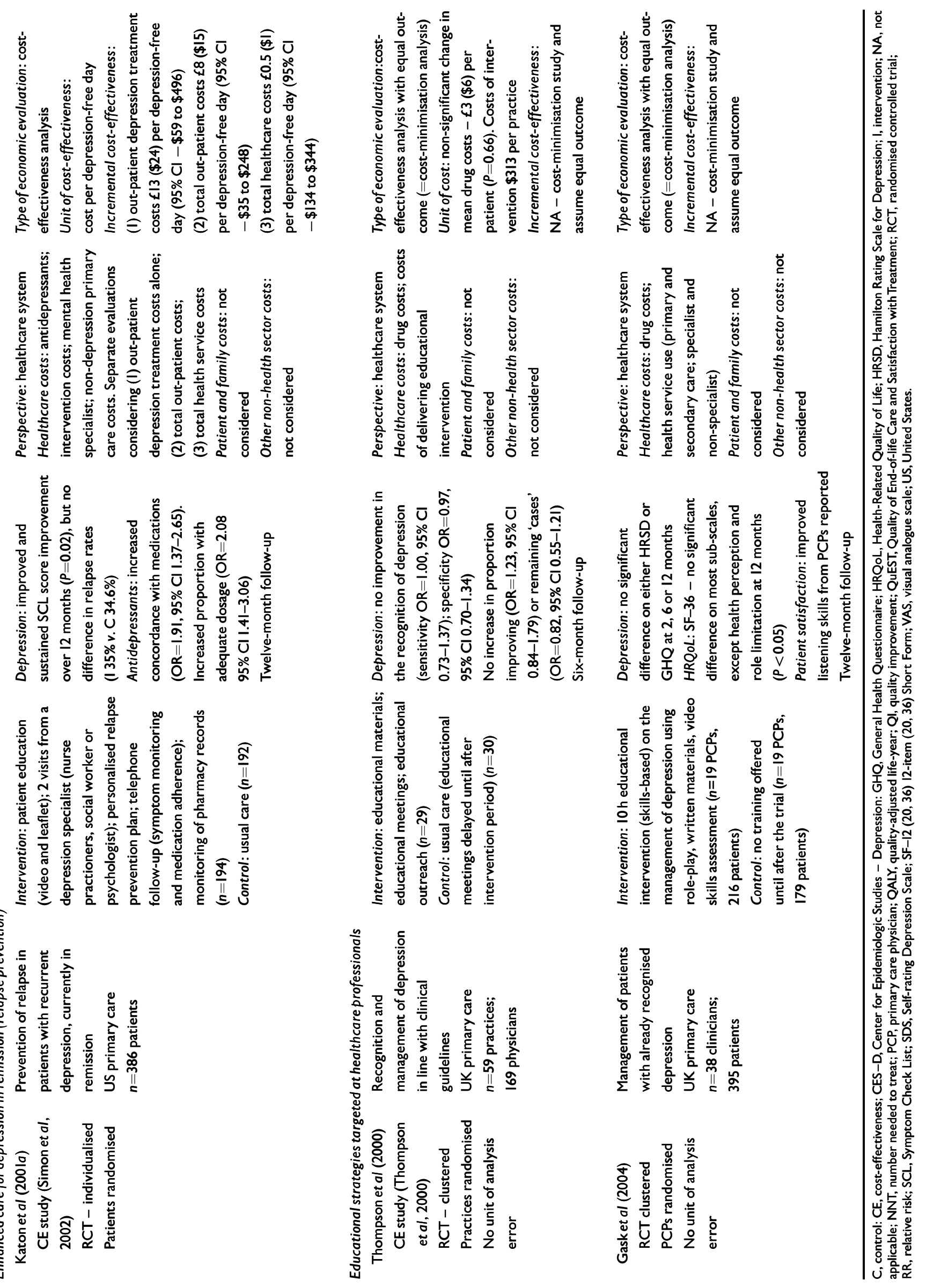


methods to generate confidence intervals around cost-effectiveness ratios (Efron \& Tibshirani, 1993) and to calculate probabilistic interpretations using cost-effectiveness thresholds and acceptability curves (Fenwick et al, 2002). Only confidence intervals and cost-effectiveness acceptability curves based upon an appropriate method were reported. We also examined whether studies had accounted for clustering when clinics and primary care physicians were the unit of randomisation (Ukoumunne et al, 1999). Failure to account for clustering within practices ('unit of analysis error') can produce spuriously tight confidence intervals and potentially misleading results (Thomas et al, 2003).

Traditional quantitative methods of synthesising clinical data such as metaanalysis are difficult to apply to economic evaluations, and ideally require individual patient-level data which are rarely available to researchers (Petitti, 2000; Bower et al, 2003). Instead, we used the schematic method of data synthesis proposed by Nixon et al (2001) and recommended in the guidelines issued by the NHS Centre for Reviews and Dissemination (2001b). This method of analysis represents incremental cost and incremental effectiveness as a tabular refinement of the costeffectiveness plane (Black, 1990), known as a 'permutation plot' (Birch \& Gaffni, 1996).

Briefly, the permutation plot visually presents nine possible outcomes (see Fig. 1), and links to the issues of technical and allocative efficiency (Donaldson $e t a l$, 2002). Interventions that are technically efficient (e.g. increased effectiveness at reduced cost) or inefficient (e.g. increased cost with reduced clinical effectiveness) can be quickly identified. Studies that raise questions of allocative efficiency and require decisions about opportunity costs and resource allocation (e.g. increased effectiveness obtained at increased cost, or reduced effectiveness obtained at reduced cost) are also identified. In constructing the permutation plot we used reported point estimates of the incremental costeffectiveness ratio (ICER) in the first in stance. Where ICERs were not available, and incremental cost and incremental effect were presented separately, we used these data to position studies within a specific permutation matrix sector. Where incremental cost data, incremental effectiveness data or incremental cost-effectiveness ratios were given with confidence intervals, we plotted only point estimates in the permutation matrix, and highlighted confidence intervals in the data tables and in the text of our review. Since cost data are often skewed (Briggs \& Gray, 1998), we report only differences and confidence intervals where an appropriate method of analysis (such as bootstrapping) was used to account for skewness, and highlight where the issue of potentially skewed cost data might have been ignored in the tables.

\section{RESULTS}

From 5873 references, our searches identified 11 full economic evaluations based upon randomised designs, providing clinical and cost-effectiveness estimates for 4757 patients with depression (Von Korff et al, 1998; Simon et al, 2000, 2001a,b, 2002; Thompson et al, 2000; Schoenbaum et al, 2001; Liu et al, 2003; Pyne et al, 2003; Gask et al, 2004). The details and results of each of these studies are presented in Table 1 and summary cost-effectiveness data are shown in the permutation plot (Fig. 1).

\section{Models of care}

The majority of studies were economic evaluations of models of enhanced care for depression, based upon collaborative care models, and were conducted within the US healthcare system (Von Korff $e t a l$, 1998; Simon et al 2000, 2001a,b, 2002; Schoenbaum et al, 2001; Liu et al, 2003; Pyne et al, 2003). Two studies, conducted in the UK, evaluated the clinical and costeffectiveness of a multidisciplinary primary care educational package designed to improve the quality of care or to implement depression management guidelines (Thompson et al, 2000; Gask et al, 2004). The majority of economic evaluations were cost-effectiveness analyses, with two costutility analyses (Schoenbaum et al, 2001; Pyne et al, 2003).

Enhanced care was offered for the management of a newly diagnosed episode of depression in 9 of the 11 studies (Von Korff et al, 1998; Simon et al, 2000, 2001a,b, 2002; Thompson et al, 2000; Schoenbaum et al, 2001; Liu et al, 2003; Pyne et al, 2003; Gask et al, 2004), with additional studies for treatment-resistant depression (Simon et al, 2001a) and relapse prevention (Simon et al, 2002). Interventions generally involved some form of clinical practice guideline, with a range of implementation strategies of varying intensity. For example, one study involved the use of brief telephone contact by non-specialist nurses to facilitate concordance with medication, to monitor progress and to coordinate follow-up (Simon et al, 2000). In other strategies, such as collaborative and stepped care programmes, a case manager coordinated care between primary care physicians and specialists, while offering brief problem-focused psychosocial interventions (Von Korff et al, 1998). The most comprehensive intervention was the Partners in Care study, which included screening, clinician and patient education, guideline dissemination, case management and enhanced access to specialist care, including cognitive-behavioural therapy (Schoenbaum et al, 2001).

\section{Details of economic evaluations}

The majority of studies examined cost and consequence from the perspective of the healthcare system or third-party payer. Costs generally included all drug, depression and non-depression-related primary care costs, together with the costs of specialist referral. Several studies considered out-patient depression treatment costs alone, before broadening the perspective of the evaluation to include first all outpatient treatment costs and then all health service costs (e.g. Simon et al, 2001a). Some studies broadened the perspective of the economic evaluation by studying patient and carer expenses and lost earnings through time in treatment (Schoenbaum et al, 2001; Pyne et al, 2003). No study considered unemployment benefits or lost earnings of patients as a consequence of illness, or wider non-healthcare costs such as social security benefits and lost earnings of carers. The period of follow-up and time horizon of the economic evaluations was generally 6-12 months, although two studies did report cost and effectiveness data at 24 months (Schoenbaum et al, 2001) and 28 months (Katon et al, 2002).

There was some degree of consistency between studies in terms of the unit of cost-effectiveness. Several studies (Simon et al, 2000, 2001a,b, 2002) reported incremental cost per depression-free day. Two cost-utility studies (Schoenbaum et al, 2001; Pyne et al, 2003) presented cost per quality-adjusted life-year (QALY) estimates by combining population utility estimates with patient-level rating scores on the short form instruments (Brazier et al, 1998; Sugar et al, 1998; Lenert et al, 2000). The degree of uncertainty around estimates of 
cost-effectiveness was expressed within confidence limits in several studies, calculated through bootstrap analysis (Efron \& Tibshirani, 1993), or expressed through cost-effectiveness acceptability curves (Fenwick et al, 2002; see Table 1).

\section{Details of cost-effectiveness estimates}

The great majority of studies (9 out of 11) demonstrated improved clinical outcomes for depression management, and all demonstrated increased point estimates of costs associated with caring for depression. These results are summarised in the permutation plot (Fig. 2).

\section{Enhanced care programmes for newly diagnosed depression}

We found seven randomised economic evaluations (Von Korff et al, 1998; Simon et al, 2000, 2001a,b, 2002; Schoenbaum et al, 2001; Liu et al, 2003; Pyne et al, 2003).

Collaborative care approaches attracted increased treatment costs associated with delivering the intervention and increased treatment costs in terms of increased primary care visits, increased use of antidepressant medication, and access to secondary care. When considering primary care depression treatment costs alone, estimates ranged from $£ 7(\$ 13$, no confidence interval given) per depression-free day (Simon et al, 2000) to $£ 13$ (\$24, $95 \%$ CI -105 to 148 ) per depression-free day (Simon et al, 2002). When the perspective of the evaluation was broadened in two studies (Simon et al, 2001b; Liu et al, 2003), there was some suggestion that increased costs associated with the intervention might be partially offset through reduced use of other services, reducing the overall cost per depression-free day. In no study was cost-offset through reduced healthcare utilisation of an extent and magnitude to make the overall programme cost-saving and dominant.

In terms of studies examining cost per QALY using tariffs from the short form instruments (Brazier et al, 1998; Lenert et al, 2000), estimates ranged from $£ 8269$ (\$15463, confidence interval not given) per QALY for a nurse-delivered case management approach (Pyne et al, 2003) to $£ 19483$ (\$36467, confidence interval not given) per QALY for a complex intervention to enhance medication management (Schoenbaum et al, 2001). Using a different method for calculating QALYs (ascribing quality-adjusted weights to the number of depression-free days; Lave et al, 1998) in this study (Schoenbaum et al, 2001), 95\% confidence intervals for case management based around medication ranged from $£ 8190$ to $£ 16380$ (\$15331 to $\$ 30663$ ), and for nurse-delivered therapy and case management from $£ 5063$ to $£ 10124$ (\$9478 to $\$ 18953$ ).

In a series of cost-effectiveness ratio acceptability estimates (Pyne et al, 2003) using cost-effectiveness acceptability thresholds, for a nurse-delivered case management approach there was a $65 \%$ probability that the cost-effectiveness of the intervention was less than $\$ 20000$ per QALY and a $91 \%$ probability that it was less than $\$ 50000$ per QALY.

\section{Enhanced care for treatment-resistant depression}

We found one randomised economic evaluation (reported in two papers: Simon et al, 2001a; Katon et al, 2002).

This stepped care approach, whereby enhanced care was reserved for those who had not responded to initial management by their general practitioner, attracted increased treatment costs in terms of increased primary care visits, increased use of antidepressant medication, and access to secondary care (Simon et al, 2001a). When out-patient costs alone were considered, improved outcome was achieved at a cost of $£ 11$ ( $\$ 21,95 \%$ CI 8 to 126 ) per depression-free day over 6 months. There was no evidence of cost offset when the perspective of the intervention was broadened to include total out-patient costs $-£ 14$ $(\$ 26,95 \%$ CI -10 to 213$)$ per depression-free day - or total healthcare costs $-£ 19(\$ 35,95 \%$ CI -52 to 388$)$ per depression-free day. Longer-term follow-up over 28 months from this same trial (Katon et al, 2002) demonstrated a persistent clinical effect, and cost differences between groups had become non-significant. However, the follow-up was limited by attrition and the low statistical power of this single study made it difficult to interpret this non-significant difference in costs.

\section{Enhanced care to prevent relapse in recurrent depression}

We found one randomised economic evaluation (Simon et al, 2002). Case management targeted at those with recurrent but remitted depression produced improved depression outcomes at 12 months. This intervention attracted increased treatment costs in terms of increased primary care visits, increased use of antidepressant medication, and access to secondary care (Simon et al, 2002). When out-patient costs alone were considered, improved outcome was achieved at a cost of $£ 13(\$ 24,95 \%$ CI -35 to 496$)$ per depression-free day over 12 months. There was some suggestion of cost offset when the perspective of the intervention was broadened to include total out-patient costs $-£ 8 \quad(\$ 15,95 \%$ CI -35 to 248$)$ per depression-free day - or total healthcare costs $-£ 0.5(\$ 1,95 \%$ CI -52 to 388$)$ per depression-free day. However, wide confidence intervals prevented firm conclusions in this respect.

\section{Clinician education strategies}

We found two randomised economic evaluations (Thompson et al, 2000; Gask et al, 2004). These studies used a purely educational approach (Thompson et al, 2000; Gask et al, 2004) and showed no impact on the improved management or outcome of depression, but attracted increased costs associated with the educational intervention. This is clearly ineffective and technically inefficient.

\section{DISCUSSION}

The main finding of this review is that there is a large and rigorous body of clinical and economic research into the enhanced management of depression in primary care. Enhancements of care, such as case management and collaborative care, mostly produce improved outcomes but are associated with increased direct healthcare costs over the short term (Von Korff et al, 1998; Simon et al, 2000, 2001a,b, 2002; Schoenbaum et al, 2001; Liu et al, 2003; Pyne et al, 2003). Educational strategies did not lead to improved clinical outcomes and were associated with increased costs (Thompson et al, 2000; Gask et al, 2004). Several issues deserve further consideration.

First, the perspective of all these evaluations was that of the healthcare provider and healthcare system. Depression has profound economic consequences, in terms of direct and indirect costs both to the individual and to wider society (Greenberg et al, 2003; Thomas \& Morris, 2003), and a consideration of these perspectives is generally more useful to policy makers (Gold $e t$ al, 1996). There is a possibility that this broader economic perspective might demonstrate 
a higher degree of cost offset and technical efficiency, and there was some evidence from some evaluations that might indeed be the case (e.g. Simon et al, 2002; Liu et al, 2003). There is now emerging evidence from randomised controlled trials (e.g. Schoenbaum et al, 2001; Rost et al, 2004) that unemployment is reduced and economic productivity increased as a consequence of case management approaches. These effects deserve to be incorporated into future randomised economic evaluations. Similarly, most of the studies examined cost-effectiveness over a 6- to 12-month perspective. One study that examined costs and consequence over a 28 -month period did suggest that excess costs associated with enhanced care in the short term had disappeared over time (Katon et al, 2002). This raises the possibility that the benefits of front-loaded intervention costs might be realised over a longer period of follow-up. It should be noted that longer-term clinical benefits of enhanced care for depression have begun to emerge (up to 5 years; Wells et al, 2004), although longer-term cost-effectiveness has not been reported at the time of writing. Further research into the longer-term cost and consequences is justified.

A second limitation of this research evidence is the failure to produce a common metric in terms of unit of cost-effectiveness to allow comparisons between competing programmes (Torgerson \& Rafterty, 1999). A substantial proportion of evaluations used cost per depression-free day as the unit of cost-effectiveness. This measure has intuitive clinical and economic meaning, and might be adopted across interventions. It is also commendable that attempts have been made to incorporate preference-based measures and to establish cost per QALY for certain interventions. The inherent appeal of this measure is the possibility of comparing net benefit across disease categories and interventions, in order to make more rational decisions about resource allocation and prioritisation (Torgerson \& Rafterty, 1999). The notion of how best to measure QALYs in the case of depression is far from clear (Sherbourne et al, 2001) and some of the findings in this review demonstrate the inconsistency of findings according to the method used. This is an area that deserves further research

The third and main issue is about deciding whether enhanced care should be funded, based on these cost-effectiveness data. Decision-makers in this case are fortunate in having recourse to a strong body of research literature on costeffectiveness to use within their decisionmaking process - in deciding priorities within healthcare systems and within mental health services. The overriding message of this systematic review is that there is a substantial opportunity to improve the outcomes of depression, and that primary care quality improvement strategies involving collaborative care and case management are a strong candidate approach. However, improving depression outcomes will require a substantial investment of funds. When considering cost per QALY estimates, we note that the health benefit that might be expected within a certain cost threshold is comparable with other interventions that are funded from within healthcare systems. In a review of the population-level impact of mental health interventions, Andrews and colleagues $(2000,2004)$ demonstrated that interventions with similar levels of expected health gain to those presented in this review can substantially reduce the population burden of illness and disability within existing healthcare budgets.

It has now been comprehensively demonstrated that educational interventions have minimal impact on clinical outcomes, unless they are supported by enhancements of care (Gilbody et al, 2003). In addition, we have clearly demonstrated that clinician education packages, when delivered alone, are a cost-ineffective strategy - bestowing no improved outcome at an increased cost. Educational strategies only become effective when they are combined with an enhancement of care such as case management. There is no case for further investment in packages based solely upon an educational design. Our review summarises cost-effectiveness data from two randomised studies of educational interventions (Thompson et al, 2000; Gask et al, 2004), but should also be considered in the context of a much larger body of evidence from randomised trials (Gilbody et al, 2003).

Fourth, the vast majority of economic data relating to collaborative care presented within this review are derived from the USA. This raises questions about the degree to which cost-effectiveness estimates of collaborative care and case management can be translated to other healthcare systems and settings. One reason to be cautious about this aspect is the fact that many depression management programmes evaluated within this review have been designed within a US managed-care system.
However, evidence is beginning to emerge of the clinical benefits of this method of organising care in European socialised healthcare systems (Vergouwen et al, 2005) and in less affluent countries and less well-financed systems (Araya et al, 2003). At the time of writing the costeffectiveness of these clinically effective non-US studies had not been reported. In the interim, technologies are available to examine cost-effectiveness between different healthcare systems, for example by combining clinical effectiveness estimates from these trials with routine service use and cost data from another healthcare setting, using decision modelling (Petitti, 2000). Our review identifies candidate interventions that can be further evaluated from the perspective of other systems and settings.

The final issue relates to the methods that have been used to summarise the cost-effectiveness literature in this review. We used a method of literature synthesis that had hitherto not been applied in this or any other area of mental health. Through the use of extensive literature searches and an explicit framework of considering the quality of the economic evidence, we have collated and summarised a large and important body of research evidence, using systematic review methodology (Gilbody \& Petticrew, 1999). Further, through the use of innovative methods of presenting economic data such as the permutation plot (Nixon et al, 2001), we believe we have simplified a complex and heterogeneous body of research evidence to make it understandable for both experts and non-experts alike. Unfortunately, the permutation plot loses much of the interesting detail of individual economic studies, such as the distribution of costs and effects, when point estimates only are plotted in sectors of the costeffectiveness plane. The results of the permutation matrix should therefore be considered alongside more detailed results of individual studies, such as those presented in data tables. However, the communication of complex health economic research to non-expert audiences is essential in ensuring that economic evidence is incorporated into rational healthcare decision-making.

\section{ACKNOWLEDGEMENTS}

We are grateful to Dr Greg Simon for providing unpublished cost-effectiveness data; to Ms Julie 
Glanville of the National Health Service Centre for Reviews and Dissemination, UK, for conducting extensive literature searches; and to anonymous peer reviewers for their helpful comments.

\section{APPENDIX}

\section{Types of economic evaluations}

Adapted from NHS Centre for Reviews and Dissemination (200la).

Full economic evaluations are studies in which a comparison of two or more treatments or care alternatives is undertaken and in which both the costs and outcomes of the alternatives are examined.

\section{Cost-benefit analysis}

Cost and outcomes are measured in monetary terms and used to calculate net monetary gains or losses (presented as a cost-benefit ratio). Increasingly used in calculating cost-benefit using the net benefit approach: see McCrone et al (2004) for an example.

\section{Cost-utility analysis}

Measures the benefits of alternative treatments or types of care by using utility measures such as quality-adjusted life-years (QALYS) and may present relative costs per QALY: see Pyne et al (2003) in this review for an example.

\section{Cost-effectiveness analysis}

Compares interventions with a common or natural outcome (such as depression severity or depression-free days) to discover which produces the maximum outcome for the same input of resources in a given population: see Simon et al (2001a) in this review for an example.

\section{Cost-minimisation analysis}

Assumes equal outcome for alternative treatments and describes which is associated with the lowest cost. Cost-effectiveness analyses based upon trials which demonstrate equal clinical outcomes are de facto cost-minimisation analyses: see Gask et al (2004) in this review for an example.

\section{REFERENCES}

Agency for Health Care Policy Research (1993) Depression in Primary Care. Washington DC: US Department of Health and Human Services.

Andrews, G., Sanderson, K., Corry, J., et al (2000) Using epidemiological data to model efficiency in reducing the burden of depression. Journal of Mental Health Policy and Economics, 3, 175-186.

Andrews, G., Issakidis, C., Sanderson, K., et al (2004) Utilising survey data to inform public policy: comparison of the cost-effectiveness of treatment of ten mental disorders. British Journal of Psychiatry, 184, 526-533.

Araya, R., Rojas, G., Fritsch, R., et al (2003) Treating depression in primary care in low income women in

SIMON GILBODY, DPhil, MRCPsych, Department of Health Sciences, University of York; PETER BOWER, PhD, National Primary Care Research \& Development Centre, University of Manchester; PAULA WHITTY, MD, FFPH, Centre for Health Services Research, University of Newcastle upon Tyne, UK

Correspondence: Dr Simon Gilbody, Department of Health Sciences, University of York, York YOI0 6DD, UK. Tel: +44 (0)1904 321370; fax: +44 (0)1904 321388; email: sg519@york.ac.uk

(First received 4 August 2005, final revision 2 December 2005, accepted 19 December 2005)

Santiago, Chile: a randomised controlled trial. Lancet, 361, 995-1000.

Bero, L., Grilli, R., Grimshaw, J., et al (1998) The Cochrane Effective Practice and Organisation of Care Group (EPOC) Module. Cochrane Library, issue 4. Oxford: Update Software.

Birch, S. \& Gaffni, A. (1996) Cost effectiveness and cost utility analyses: methods for the non economic evaluation of healthcare programs and how we can do better. In Managing Technology in Healthcare (eds E. Geisler \& O. Heller), pp. 5I-67. Norwell, MA: Kluwer Academic.

Black, W. C. (1990) The CE plane: a graphic representation of cost-effectiveness. Medical Decision Making, 10, 21-24

Bower, P. \& Gilbody, S. (2005) Managing common mental health disorders in primary care: conceptual models and evidence base. BMJ, 330, 839-842.

Bower, P., Byford, S., Barber, J., et al (2003) Metaanalysis of data on costs from trials of counselling in primary care: using individual patient data to overcome sample size limitations in economic analyses. BMJ, 326, 1247-1250.

Brazier, J., Usherwood, T., Harper, R., et al (1998) Deriving a preference-based single index from the UK SF-36 Health Survey. Journal of Clinical Epidemiology, 5I, III5-II28.

Briggs, A. \& Gray, A. (1998) The distribution of health care costs and their statistical analysis for economic evaluation. Journal of Health Services Research and Policy, 3, 233-245.

\section{Cabana, M. D., Rushton, J. L. \& Rush, A. J. (2002)} Implementing practice guidelines for depression: applying a new framework to an old problem. General Hospital Psychiatry, 24, 35-42.

Donaldson, C., Currie, G. \& Mitton, C. (2002) Cost effectiveness analysis in health care. BMJ, 325, 891-894.

Drummond, M. F. \& Jefferson, T. O. (1996) Guidelines for authors and peer reviewers of economic submissions to the BMJ. BMJ, 313, 275-283.

Drummond, M. F., O'Brien, B., Stoddard, G. L., et al (1997) Methods for the Economic Evaluation of Health Care Programmes. Oxford: Oxford University Press.

Efron, B. \& Tibshirani, R. (1993) An Introduction to the Bootstrap. New York: Chapman \& Hall.

Fenwick, L., Claxton, K. \& Schulpher, M. (2002) Representing uncertainty: the role of cost-effectiveness acceptability curves. Health Economics, 10, 779-787.

Gask, L., Dowrick, C., Dixon, C., et al (2004) A pragmatic cluster randomized controlled trial of an educational intervention for GPs in the assessment and management of depression. Psychological Medicine, 34, 63-72.

Gilbody, S. M. \& Petticrew, M. (1999) Rational decision making in mental health: the role of systematic reviews in clinical and economic evaluation. Journal of Mental Health Policy and Economics, 2, 99-107.

Gilbody, S., Whitty, P., Grimshaw, J., et al (2003) Educational and organizational interventions to improve the management of depression in primary care: a systematic review. JAMA, 289, 3145-3I5I.

Gold, M. R., Siegel, J. E., Russell, L. B., et al (1996) Cost effectiveness in Health and Medicine. New York: Oxford University Press.

Greenberg, P. E., Kessler, R. C., Birnbaum, H. G., et al (2003) The economic burden of depression in the United States: how did it change between 1990 and 2000? Journal of Clinical Psychiatry, 64, 1465-1475.

Hedrick, S. C., Chaney, E. F., Felker, B., et al (2003) Effectiveness of collaborative care depression treatment in Veterans' Affairs primary care. Journal of General Internal Medicine, 18, 9-16.

Katon, W., Von Korff, M., Lin, E., et al (1995) Collaborative management to achieve treatment guidelines. Impact on depression in primary care. JAMA, 273, |026-103|.

Katon, W., Robinson, P., Von Korff, M., et al (1996) A multifaceted intervention to improve treatment of depression in primary care. Archives of General Psychiatry, 53, 924-932.

Katon, W., Von Korff, M., Lin, E., et al (1999) Stepped collaborative care for primary care patients with persistent symptoms of depression: a randomized trial. Archives of General Psychiatry, 56, II09-III5.

Katon, W., Rutter, C., Ludman, E. J., et al (200la) A randomized trial of relapse prevention of depression in primary care. Archives of General Psychiatry, 58, 24I-247.

Katon, W., Van Korff, M., Lin, E., et al (200Ib) Rethinking practitioner roles in chronic illness: the specialist primary care physician and the practice nurse. General Hospital Psychiatry, 23, 138-144.

Katon, W., Russo, J., Von Korff, M., et al (2002) Long term effects of a collaborative care intervention in persistently depressed primary care patients. Journal of General Internal Medicine, 17, 741-748.

Katzelnick, D. J., Simon, G. E., Pearson, S. D., et al (2000) Randomized trial of a depression management program in high utilizers of medical care. Archives of Family Medicine, 9, 345-35I.

Lave, J. R., Frank, R. G., Schulberg, H. C., et al (1998) Cost-effectiveness of treatments for major depression in primary care practice. Archives of General Psychiatry, 55 645-65I.

Lenert, L. A., Sherbourne, C. D., Sugar, C., et a (2000) Estimation of utilities for the effects of depression from the SF-12. Medical Care, 38, 763-770.

Liu, C. F., Hedrick, S. C., Chaney, E. F., et al (2003) Cost-effectiveness of collaborative care for depression in a primary care veteran population. Psychiatric Services, 54, 698-704. 
McCrone, P., Knapp, M., Proudfoot, J., et al (2004) Cost-effectiveness of computerised cognitivebehavioural therapy for anxiety and depression in primary care: randomised controlled trial. British Journal of Psychiatry, 185, 55-62.

National Institute for Clinical Excellence (2004) Depression: Core Interventions in the Management of Depression in Primary and Secondary Care. London: NICE.

National Institute for Mental Health in England (2004) Enhanced Services Specificaton for Depression Under the New GP Contract. Manchester: NIMHE North West.

NHS Centre for Reviews and Dissemination (200la) Making Cost-Effectiveness Information Available: The NHS Economic Evaluation Database Project. CRD Report 6 (2nd edn). York: University of York.

NHS Centre for Reviews and Dissemination (200lb) Undertaking Systematic Reviews of Research on Effectiveness: CRD Report 4 (2nd edn). York: University of York.

Nixon, J., Khan, K. S. \& Kleijnen, J. (200I) Summarising economic evaluations in systematic reviews: a new approach. BMJ, 322, 1596-1598.

Paykel, E. S. \& Priest, R. G. (1992) Recognition and management of depression in general practice: consensus statement. BMJ, 305, 1198-1202.

Petitti, D. B. (2000) Meta Analysis, Decision Analysis and Cost-Effectiveness Analysis. Oxford: Oxford University Press.

Pyne, J. M., Rost, K. M., Zhang, M., et al (2003) Cost effectiveness of a primary care depression intervention. Journal of General Internal Medicine, 18, 432-44I.

Rost, K., Nutting, P. A., Smith, J., et al (200I) Improving depression outcomes in community primary care practice: a randomised trial of the QuEST intervention. Journal of General Internal Medicine, 16 143-149.

Rost, K., Smith, J. L. \& Dickinson, M. (2004) The effect of improving primary care depression management on employee absenteeism and productivity. A randomized trial. Medical Care, 42. 1202-1210.

Schoenbaum, M., Unutzer, J., Sherbourne, C., et al (200I) Cost-effectiveness of practice-initiated quality improvement for depression: results of a randomized controlled trial. JAMA, 286, 1325-1330.

Sherbourne, C. D., Unutzer, J., Schoenbaum, M., et al (200I) Can utility-weighted health-related qualityof-life estimates capture health effects of quality improvement for depression? Medical Care, 39. 1246-1259.

Simon, G. E., Von Korff, M., Rutter, C., et al (2000) Randomised trial of monitoring, feedback, and management of care by telephone to improve treatment of depression in primary care. BMJ, 320, 550-554.

Simon, G. E., Katon, W. J., Von Korff, M., et al (200la) Cost-effectiveness of a collaborative care program for primary care patients with persistent depression. American Journal of Psychiatry, 158, 1638-1644.

Simon, G. E., Manning, W. G., Katzelnick, D. J., et al (200lb) Cost-effectiveness of systematic depression treatment for high utilizers of general medical care. Archives of General Psychiatry, 58, 181-187.

Simon, G. E., Von Korff, M., Ludman, E. J., et al (2002) Cost-effectiveness of a program to prevent depression relapse in primary care. Medical Care, 40 , 94I-950.

Sugar, C. A., Sturm, R., Lee, T. T., et al (1998) Empirically defined health states for depression from the SF-12. Health Service Research, 33, 911-928.
Thomas, C. M. \& Morris, S. (2003) Cost of depression among adults in England in 2000. British Journal of Psychiatry, 183, 514-519.

Thomas, R. E., Ramsay, C. R., McAuley, L., et al (2003) Unit of analysis errors should be clarified in meta-analyses. BMJ, 326, 397.

Thompson, C., Kinmonth, A. L., Stevens, L., et al (2000) Effects of clinical-practice guideline and practicebased education on detection and outcome of depression in primary care: Hampshire Depression project randomised controlled trial. Lancet, $\mathbf{3 5 5}$ |85-19|.

Torgerson, D. \& Rafterty, J. (1999) Measuring outcomes in economic evaluations. BMJ, 318, 1413 .

Ukoumunne, O. C., Gulliford, M. C., Chinn, S., et al (1999) Methods in health service research. Evaluation of health interventions at area and organisation level. BMJ, 319 . 376-379.

Vergouwen, A. C., Bakker, A., Burger, H., et al (2005) A cluster randomized trial comparing two interventions to improve treatment of major depression in primary care. Psychological Medicine, 35, 25-33.

Von Korff, M., Katon, W., Bush, T., et al (1998) Treatment costs, cost offset, and cost-effectiveness of collaborative management of depression. Psychosomatic Medicine, 60, 143-149.

Wells, K. A., Sherbourne, C., Schoenbaum, M., et al (2000) Impact of disseminating quality improvement programmes for depression in managed primary care: a randomized controlled trial. JAMA, 283, 212-220.

Wells, K., Sherbourne, C., Schoenbaum, M., et a (2004) Five-year impact of quality improvement for depression: results of a group-level randomized controlled trial. Archives of General Psychiatry, 6I 378-386. 